\title{
SOLID-STATE PROPERTIES AND SOLUBILITY STUDIES OF NOVEL PHARMACEUTICAL COCRYSTAL OF ITRACONAZOLE
}

\section{STEVANUS HIENDRAWAN, BAMBANG VERIANSYAH, RAYMOND R. TJANDRAWINATA*}

Dexa Laboratories of Biomolecular Sciences, Cikarang 17550, West Java, Indonesia

Email: raymond@dexa-medica.com

Received: 12 Apr 2018, Revised and Accepted: 09 Jul 2018

\section{ABSTRACT}

Objective: Pharmaceutical cocrystal is a promising method to improve the solubility of active pharmaceutical ingredients (APIs). Itraconazole (ITZ) is a BCS class II antifungal drug with poor aqueous solubility, therefore an attempt was made to improve the solubility of ITZ using cocrystallization technique. In this work, six novel pharmaceutical cocrystals of ITZ with various coformers, including 4-hydroxybenzoic acid (4HBA), trans-cinnamic acid (TCA), suberic acid (SUB), sebacic acid (SBC), 1-hydroxy-2-naphthoic acid (1H2N), and benzamide (BZD) were prepared.

Methods: ITZ cocrystals was prepared by solvent evaporation process. The cocrystals produced were characterized using powder x-ray diffraction (PXRD), differential scanning calorimetry (DSC), thermogravimetric analysis (TGA) and fourier transform infrared (FTIR) spectroscopy. Solubility analysis was performed to evaluate the cocrystals.

Results: PXRD and DSC analysis revealed that the pattern of all ITZ cocrystals was distinguishable from the individual compounds which indicates the formation of new phase. The solubility of ITZ and its cocrystals from highest to lowest after $24 \mathrm{~h} \mathrm{in} 0.1 \mathrm{~N} \mathrm{HCl} \mathrm{solution} \mathrm{(pH} \mathrm{1.2)} \mathrm{follows} \mathrm{the} \mathrm{order}$ ITZ-TCA (1.97-fold), ITZ-SBC (1.09-fold), ITZ, ITZ-1H2N (0.58-fold) and ITZ-4HBA (0.46-fold).

Conclusion: This study demonstrates that the selection of coformers has pronounced an impact on the physicochemical properties of ITZ. Based on this study, it can be concluded that cocrystallization offers a valuable way to improve the solubility of ITZ.

Keywords: Crystal engineering, Cocrystal, Itraconazole, Solubility

(C) 2018 The Authors. Published by Innovare Academic Sciences Pvt Ltd. This is an open access article under the CC BY license (http://creativecommons.org/licenses/by/4.0/) DOI: http://dx.doi.org/10.22159/ijap.2018v10i5.26663

\section{INTRODUCTION}

Itraconazole (ITZ) is a potent synthetic triazole antifungal with activities against various fungal infections including histoplasmosis, blastomycosis and oncomycosis [1]. ITZ belongs to class II of the biopharmaceutics classification system (BCS) with low solubility and high permeability. Its aqueous solubility is estimated at approximately $1 \mathrm{ng} / \mathrm{ml}$ at neutral $\mathrm{pH}$ and $5 \mu \mathrm{g} / \mathrm{ml}$ at $\mathrm{pH} 1 \mathrm{which}$ indicate a poor oral bioavailability (55\%) [2]. Due to its extremely low solubility, there is a practical demand to improve the solubility and therefore the oral bioavailability of ITZ. Different strategies to improve the aqueous solubility and dissolution rate have been described in the literature, such as cyclodextrin complexation [3], solid dispersions [4] and self-emulsifying drug delivery system (SEDDS) [5]. In addition, adsorption on ordered mesoporous silica has also been reported by other researchers [6].

Crystal engineering has become one of the most effective strategies to improve the physicochemical properties of various active pharmaceutical ingredients (APIs). This concept has widely been explored in designing multicomponent solid forms of APIs which possess unfavorable physicochemical properties. Pharmaceutical polymorphs, cocrystals and salts formations are few examples on the utilization of crystal engineering of overcoming the poor solubility of several APIs [7]. Different polymorphic forms of ITZ were reported in previous publications, which showed three polymorphic forms of ITZ (forms I-III) [8, 9]. Salt formation is the first choice of method to increase solubility, dissolution rate and bioavailability of poorly soluble APIs [10]. Compared to other multicomponent crystals, such as cocrystals or eutectic mixtures, pharmaceutical salts are the most preferred solid-state form to achieve solubility enhancement [11]. Therefore, it is understandable that almost $50 \%$ of currently marketed APIs are in the form of salts [10]. However, salt formation is feasible to be done when the API possesses a suitable ionizable site [12]. The utility of salts is also limited by their hygroscopicity character due to the ionic nature of the crystal [13]. On the other hand, the salt formation of very weak base APIs such as ITZ also presents a greater risk of disproportionation [14].
During the past few years, interest in cocrystals research as an alternative way to modify the physicochemical properties of APIs has been increased significantly in the pharmaceutical sector. Pharmaceutical cocrystal may be defined as a molecular complex of an API with one or more cocrystal formers (CCFs) in a well-defined stoichiometry through hydrogen bonds or other non-covalent interactions, such as hydrogen bonds, $\pi-\pi$ stacking, and van der Waals interactions [15]. Apart from the potential improvement in solubility aspect [16], pharmaceutical cocrystals have already been proven to be useful in improving stability [17], hygroscopicity [18], mechanical properties [19] and bioavailability, while still maintaining the pharmacological activity of the drug [20]. In addition, cocrystal formation also provides the opportunities for the pharmaceutical industry to create intellectual properties and patents of APIs to extend their life cycle [21].

Pharmaceutical salts and co-crystals of ITZ with various counterions and coformers have previously been reported. Remenar et al. [22] synthesized ITZ cocrystals with 1,4-dicarboxylic acids (fumaric, succinic, l-malic, l-, d-and dl-tartaric acid) as the coformers. It was reported that ITZ-l-malic cocrystal showed a similar dissolution rate compared to the commercial product containing amorphous ITZ. Tarsa et al. [23] have reported the formation of ITZ cocrystals and salts with hydrochloric, fumaric, maleic, phosphoric, succinic and 1,5-naphthalene disulfonic acids. The formation of ITZ ditosylate salt with enhanced solubility and dissolution rate has also been studied by Kumar et al. [24]. Futhermore, ITZ cocrystals with oxalic, adipic, malonic, glutaric and pimelic acids were successfully synthesized by other researchers [25].

Crystal engineering strategies is applied in the preparation of novel cocrystals by the identification of a potential functional group, which can be utilized in the formation of supramolecular synthon. As shown in Scheme 1, ITZ possesses triazole group, which is well known to form robust $\mathrm{O}-\mathrm{H} \cdots \mathrm{N}$ heterosynthons with carboxylic acids. Solvent evaporation is the most commonly used method for cocrystallization which includes supersaturation of the solution by evaporation, cooling or addition of solubility changing solvent 
(solvent mixture or anti-solvent) [26]. In this work, novel pharmaceutical cocrystals of ITZ with 4-hydroxybenzoic acid (4HBA), trans-cinnamic acid (TCA), suberic acid (SUB), sebacic acid (SBC), 1-hydroxy-2-naphthoic acid (1H2N) and benzamide (BZD) were prepared by a solvent evaporation method (see Scheme 1). The physicochemical properties of the prepared ITZ cocrystals were further characterized by powder x-ray diffraction (PXRD), differential scanning calorimetry (DSC), thermogravimetric analysis (TGA), fourier transform infrared (FTIR) spectroscopy and solubility study.

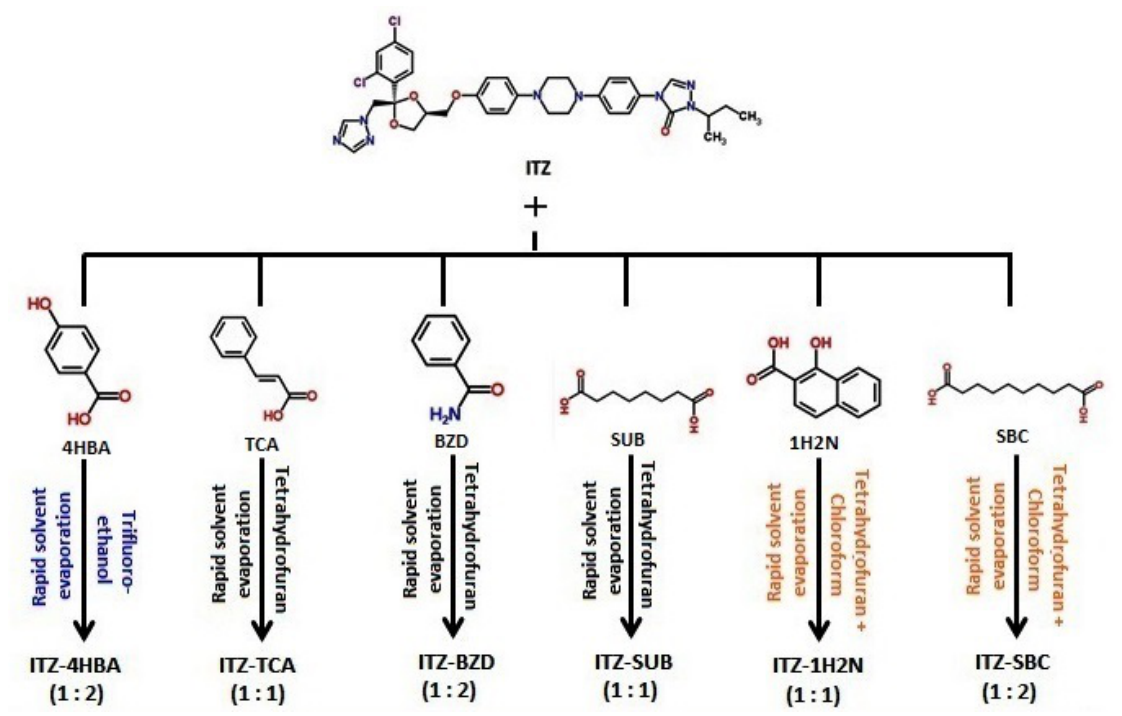

Scheme 1: Experimental condition and product obtained with the stoichiometric ratio in the reaction between ITZ and coformers

\section{MATERIALS AND METHODS}

\section{Materials}

Itraconazole (ITZ) was purchased from Metrochem API Pvt Ltd (Hyderabad, India). 4-hydroxybenzoic acid (4HBA), trans-cinnamic acid (TCA), suberic acid (SUB), sebacic acid (SBC), 1-hydroxy-2naphthoic acid $(1 \mathrm{H} 2 \mathrm{~N})$ and benzamide (BZD) were obtained from Sigma-Aldrich Co. (MO, USA). Tetrahydrofuran (ACS grade), trifluoroethanol (ACS grade), chloroform (ACS grade), trifluoroacetic acid (ACS grade) and acetonitrile (HPLC grade) were obtained from Merck KGaA (Darmstadt, Germany).

\section{Preparation of itraconazole-4-hydroxybenzoic acid cocrystal (ITZ-4HBA)}

Molar quantities of ITZ and 4HBA (1:2 mole ratio) were dissolved in $20 \mathrm{ml}$ trifluoroethanol and mixed under sonication at $40^{\circ} \mathrm{C}$ for $30 \mathrm{~min}$. The resulting solution was placed into a crystallizing disk and heated at $70{ }^{\circ} \mathrm{C}$ for $5 \mathrm{~h}$ using a hot plate to evaporate the solvent. The dried solid was collected and placed in the glass vial for further analysis.

\section{Preparation of itraconazole-trans-cinnamic acid cocrystal (ITZ- TCA)}

Equimolar quantities of ITZ and TCA (1:1 mole ratio) were dissolved in $20 \mathrm{ml}$ tetrahydrofuran and mixed under sonication at $40^{\circ} \mathrm{C}$ for $30 \mathrm{~min}$. The resulting solution was placed into a crystallizing disk and heated at $70{ }^{\circ} \mathrm{C}$ for $5 \mathrm{~h}$ using a hot plate to evaporate the solvent. The dried solid was collected and placed in the glass vial for further analysis.

\section{Preparation of itraconazole-suberic acid cocrystal (ITZ-SUB)}

Equimolar quantities of ITZ and SUB (1:1 mole ratio) were dissolved in $20 \mathrm{ml}$ tetrahydrofuran and mixed under sonication at $40^{\circ} \mathrm{C}$ for 30 min. The resulting solution was placed into a crystallizing disk and heated at $70^{\circ} \mathrm{C}$ for $5 \mathrm{~h}$ using a hot plate to evaporate the solvent. The dried solid was collected and placed in the glass vial for further analysis.

\section{Preparation of itraconazole-benzamide cocrystal (ITZ-BZD)}

Molar quantities of ITZ and BZD (1:2 mole ratios) were dissolved in $20 \mathrm{ml}$ tetrahydrofuran and mixed under sonication at $40{ }^{\circ} \mathrm{C}$ for 30 min. The resulting solution was placed into a crystallizing disk and heated at $70^{\circ} \mathrm{C}$ for $5 \mathrm{~h}$ using a hot plate to evaporate the solvent. The dried solid was collected and placed in the glass vial for further analysis.

Preparation of itraconazole-1-hydroxy-2-naphthoic acid cocrystal (ITZ-1H2N)

Molar quantities of ITZ and 1H2N (2: 1-mole ratios) were dissolved in $20 \mathrm{ml}$ tetrahydrofuran and chloroform $(1: 1, \mathrm{v} / \mathrm{v})$ solutions and mixed under sonication at $40^{\circ} \mathrm{C}$ for $30 \mathrm{~min}$. The resulting solution was placed into a crystallizing disk and heated at $70^{\circ} \mathrm{C}$ for $5 \mathrm{~h}$ using a hot plate to evaporate the solvent. The dried solid was collected and placed in the glass vial for further analysis.

\section{Preparation of itraconazole-sebacic acid cocrystal (ITZ-SBC)}

Molar quantities of ITZ and SBC (1:2 mole ratios) were dissolved in $20 \mathrm{ml}$ tetrahydrofuran and chloroform $(1: 1, \mathrm{v} / \mathrm{v})$ solutions and mixed under sonication at $40{ }^{\circ} \mathrm{C}$ for $30 \mathrm{~min}$. The resulting solution was placed into a crystallizing disk and then heated at $70{ }^{\circ} \mathrm{C}$ for $5 \mathrm{~h}$ using a hot plate to evaporate the solvent. The dried solid was collected and placed in the glass vial for further analysis.

\section{Powder X-ray diffraction (PXRD)}

The PXRD patterns were collected by a Rigaku Ultima IV X-ray diffractometer (Rigaku Co., Tokyo, Japan) using $\mathrm{Cu} K \alpha$ radiation $(\lambda=$ $1.54 \AA$ ) , a tube voltage of $40 \mathrm{kV}$ and a tube current of $40 \mathrm{~mA}$. Data were collected from 2 to $40^{\circ}$ at a continuous scan rate of $4 \% \mathrm{~min}$.

\section{Differential scanning calorimetry (DSC)}

Thermal analysis of the samples was performed on a DSC Q20 (TA Instruments Inc., New Castle, DE, USA) which was calibrated for temperature and cell constants using indium. Samples (2-5 mg) crimped in aluminum pans were analyzed from 50 to $250{ }^{\circ} \mathrm{C}$ at a heating rate of $10{ }^{\circ} \mathrm{C} / \mathrm{min}$. Samples were continuously purged with nitrogen at $50 \mathrm{ml} / \mathrm{min}$. The peak transition temperatures of samples were analyzed using Universal Analysis software (TA Instruments Inc., New Castle, DE, USA).

\section{Thermogravimetric analysis (TGA)}

TGA was performed on a TGA Q50 (TA Instruments Inc., New Castle, DE, USA) instrument. Approximately 2-5 mg samples were heated 
from 50 to $400{ }^{\circ} \mathrm{C}$ in open aluminium pans at a rate of $10{ }^{\circ} \mathrm{C} / \mathrm{min}$ under a nitrogen purge at a flow rate of $50 \mathrm{ml} / \mathrm{min}$. TGA data were analyzed using Universal Analysis software (TA Instruments Inc., New Castle, DE, USA).

\section{Fourier transform infrared (FTIR) spectroscopy}

FTIR spectra of the compounds were recorded on an FTIR type ALPHA infrared spectrometer (BRUKER, MA, USA) in platinum attenuated total reflectance (ATR) mode at a wavenumber range of $4000-700 \mathrm{~cm}^{-1}$ with a resolution of $4 \mathrm{~cm}^{-1}$.

\section{High-performance liquid chromatography (HPLC)}

Concentrations of ITZ in solutions were determined by Waters Alliance HPLC system which includes Waters e2695 separation module, Waters 2489 UV detector and $4.6 \times 150 \mathrm{~mm}$ Atlantis dC18, 5 $\mu \mathrm{m}$ column (Waters Corporation, Milford, MA). The mobile phase consisted of acetonitrile: trifluroacetic acid $0.1 \%(55: 45, \% \mathrm{v} / \mathrm{v})$ at a flow rate of $1.0 \mathrm{ml} / \mathrm{min}$. ITZ was detected at $261 \mathrm{~nm}$. The injection volume was $20 \mu \mathrm{l}$. Data acquisition and analysis were performed using Empower 2.0 software (Waters Corporation, Milford, MA).

\section{Determination of drug content}

Accurately weighed amount of each of ITZ cocrystal was dissolved in tetrahydrofuran. The solution was filtered through $0.22 \mu \mathrm{m}$ PTFE syringe filter (Whatman, USA). ITZ contents were assayed by HPLC $(\mathrm{n}=3)$.

\section{Solubility measurements}

Excessive amount of samples ( $400 \mathrm{mg}$ ) were suspended in $0.1 \mathrm{~N} \mathrm{HCl}$ solution ( $\mathrm{pH} 1.2)$ using screw-capped glass vials. The suspensions were stirred using a magnetic stirrer at a temperature of $37^{\circ} \mathrm{C}$. After $24 \mathrm{~h}$, the suspensions were filtered through a paper filter at room temperature. Solid filtrates were then dried and used for further PXRD analysis. The resulting solutions were filtered again through a $0.22 \mu \mathrm{m}$ nylon syringe filter (Whatman, USA) at room temperature. The filtered aliquots were sufficiently diluted and concentrations of ITZ in solutions were further analyzed using HPLC.

\section{RESULTS AND DISCUSSION}

The formation of cocrystal or salt is generally guided by a thumb rule of $\Delta \mathrm{pKa}(\Delta \mathrm{pKa}=\mathrm{pKa}$ (base)-pKa(acid)) value between API and coformer. In a previous study [27], it is highlighted that if $\Delta \mathrm{pKa}<-1$, cocrystal formation is expected, whereas in the region $\Delta \mathrm{pKa}>4$, the salt is more common. If $\Delta \mathrm{pKa}$ lies in between $-1 \leq \Delta \mathrm{pKa} \leq 4$, then the prediction of proton transfer is ambiguous. With regards to the ambiguity, the resultant product may be a salt or cocrystal, therefore, the cocrystals are further needed to be analyzed [27]. The pKa values of ITZ and coformers and $\Delta \mathrm{pKa}$ values are listed in table 1 .

Table 1: $\mathrm{pKa}$ values of ITZ and organic acids

\begin{tabular}{|c|c|c|}
\hline Sample & pKa & $\Delta \mathrm{pK} a$ \\
\hline ITZ & 3.70 & -- \\
\hline TCA & 4.44 & -0.74 \\
\hline $4 \mathrm{HBA}$ & 4.54 & -0.84 \\
\hline SUB & 4.15 & -0.45 \\
\hline $1 \mathrm{H} 2 \mathrm{~N}$ & 3.02 & 0.68 \\
\hline SBC & 4.72 & -1.02 \\
\hline BZD & 23.35 & -19.65 \\
\hline
\end{tabular}

\section{Powder X-ray diffraction (PXRD) analysis}

PXRD is a reliable technique to identify the formation of a new crystalline phase in solid state. Every crystalline phase of a compound exhibited its own characteristic PXRD pattern, thus PXRD analysis is commonly used to distinguish the resulting products from the starting materials [28]. PXRD patterns of ITZ, coformers, physical mixture between ITZ and coformer (PM) and their multicomponent crystals are shown in fig. 1. The details of characteristic diffraction peaks are presented in table 2. PXRD spectrum in fig. 1 revealed that novel crystalline forms which were distinct from the starting components have been generated. This can be explained on the basis of changes in internal crystal structure due to the interaction between API and coformers [29].
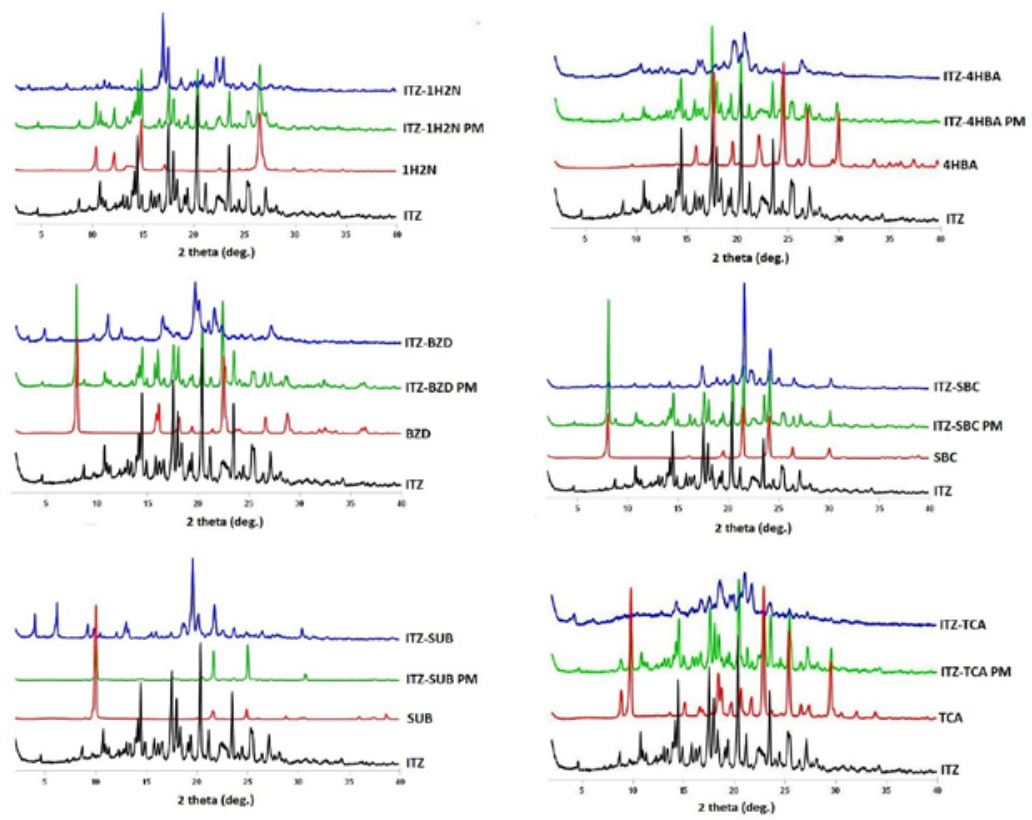

Fig. 1: Powder X-ray diffractograms of ITZ and its cocrystal 
Table 2: The characteristics diffraction peaks of ITZ, coformers and its multicomponent crystals

\begin{tabular}{ll}
\hline & $\mathbf{2 \theta}$ (degrees) \\
\hline ITZ & $14.140 ; 14.440 ; 17.500 ; 17.960 ; 20.340 ; 23.460$ \\
TCA & $8.840 ; 9.800 ; 18.400 ; 22.880 ; 25.380 ; 29.480$ \\
ITZ-TCA & $4.220 ; 14.300 ; 16.640 ; 18.520 ; 21.020 ; 23.560$ \\
4HBA & $17.640 ; 19.520 ; 22.080 ; 24.500 ; 26.880 ; 29.940$ \\
ITZ-4HBA & $10.320 ; 16.040 ; 19.560 ; 20.600 ; 20.840 ; 26.280$ \\
SUB & $9.960 ; 20.040 ; 21.540 ; 24.860 ; 28.740$ \\
ITZ-SUB & $3.980 ; 6.160 ; 12.960 ; 18.620 ; 19.520 ; 21.720$ \\
1H2N & $10.300 ; 12.120 ; 14.760 ; 17.080 ; 22.520 ; 26.480$ \\
ITZ-1H2N & $11.160 ; 16.980 ; 17.460 ; 18.720 ; 22.220 ; 22.880$ \\
SBC & $7.980 ; 19.440 ; 21.400 ; 23.980 ; 26.320 ; 29.980$ \\
ITZ-SBC & $14.080 ; 17.380 ; 20.400 ; 21.520 ; 22.320 ; 24.100$ \\
BZD & $8.020 ; 16.080 ; 18.060 ; 22.460 ; 26.600 ; 28.740$ \\
ITZ-BZD & $4.820 ; 11.080 ; 12.380 ; 16.480 ; 19.660 ; 21.580$ \\
\hline
\end{tabular}

\section{Thermal analysis}

Thermal analytical techniques, such as DSC and TGA, are commonly used to analyze the properties of a material and investigate the possible interactions between multiple components in a formulation. DSC is a very useful thermoanalytical method in the characterization of solid-state interactions between drug and coformers through the appearance, shifts or disappearance of endothermal effects [19]. DSC thermograms of ITZ, coformers and ITZ cocrystals are shown in fig. 2. Melting temperature data from DSC thermograms are summarized in table 3 . The distinct cocrystals melting point compared to those of the individual components indicated the interaction between ITZ and coformers to produce novel crystalline phase. DSC thermograms of ITZ cocrystals, except ITZ-BZD and ITZ-SBC, showed a single and sharp melting endotherm which indicated the purity of cocrystals. In the case of ITZ-BZD cocrystal, an additional small endothermic peak can be observed after the melting point which may be caused by the decomposition, as confirmed by the TGA curve. Thermogram of ITZ-SBC also showed an additional small endothermic peak which is very close to the major endotherm at $123.50{ }^{\circ} \mathrm{C}$ which may be caused by the presence of small excess of starting compounds that forms the eutectic phase. The altered melting points of ITZ cocrystals as compared to ITZ and each coformers might be attributable to the intermolecular interaction (hydrogen bonding interaction) between API and coformers that might alter the packing arrangement, crystal lattice and change in crystal structure of molecules in the cocrystals $[29,30]$.

A statistical study by Perlovich [31] on 727 cocrystal systems indicated that majority of cocrystals (55.3\%) had melting points in between those of the drug and coformers, while $15.8 \%$ of cocrystals possessed higher melting point and $28.9 \%$ showed lower melting point than those of individual compounds. An analysis of the correlation between melting points of coformers and cocrystals can provide simple rules for the rational choice of coformers in the design of cocrystals with desirable thermal properties [32]. Melting points of cocrystals were found to be correlated to melting points of coformers in a linear regression. A very good correlation coefficient of 0.9426 was found in this study (fig. 3), which means that melting points of cocrystals were well-correlated to the melting points of coformers. Therefore, it is possible to modify the melting point of ITZ cocrystals by considering the melting point of the coformers. Such association has previously been published for a series of AMG 517 cocrystals with various acids [32].
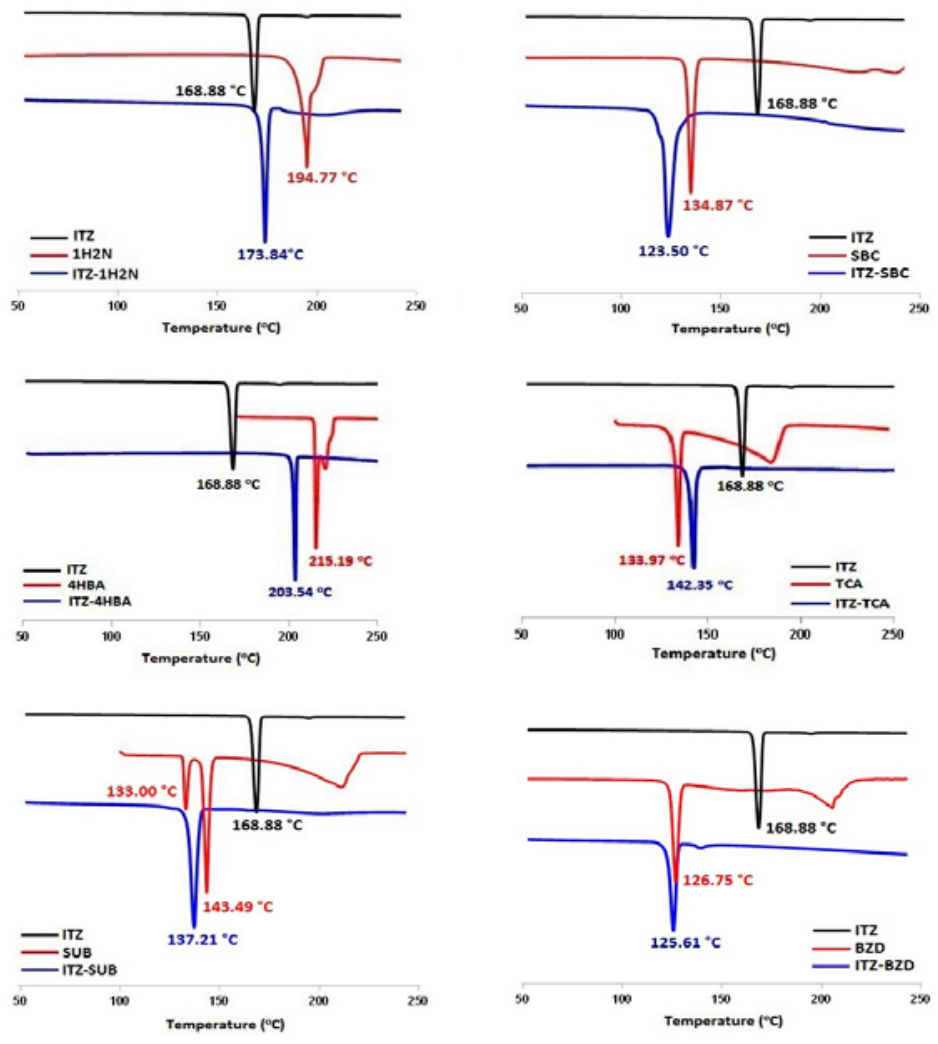

Fig. 2: DSC thermograms of ITZ and its cocrystals 
Table 3: Melting point of ITZ, coformers and ITZ cocrystals

\begin{tabular}{lll}
\hline Sample & Melting point of ITZ or coformers $\left({ }^{\circ} \mathbf{C}\right)$ & Melting point of ITZ cocyrstal $\left({ }^{\circ} \mathbf{C}\right)$ \\
\hline ITZ & 168.88 & - \\
ITZ-TCA & 133.97 & 142.35 \\
ITZ-4HBA & 215.19 & 203.54 \\
ITZ-SUB & 143.49 & 137.21 \\
ITZ-1H2N & 194.77 & 173.84 \\
ITZ-SBC & 134.87 & 123.50 \\
ITZ-BZD & 126.75 & 125.61 \\
\hline
\end{tabular}

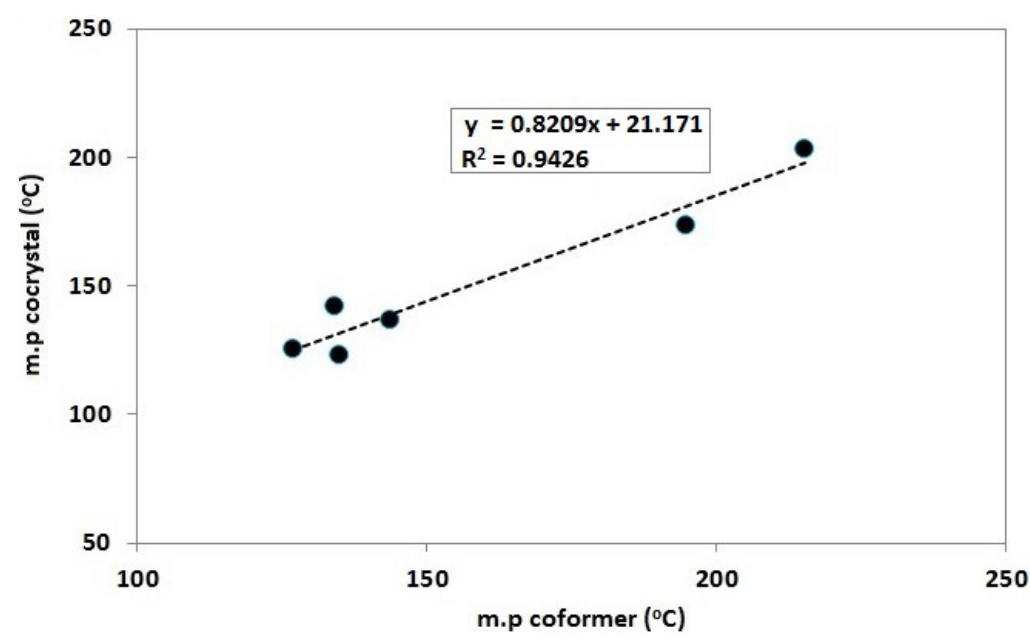

Fig. 3: Correlation between melting point (m. p) cocrystals versus melting point (m. p) coformers
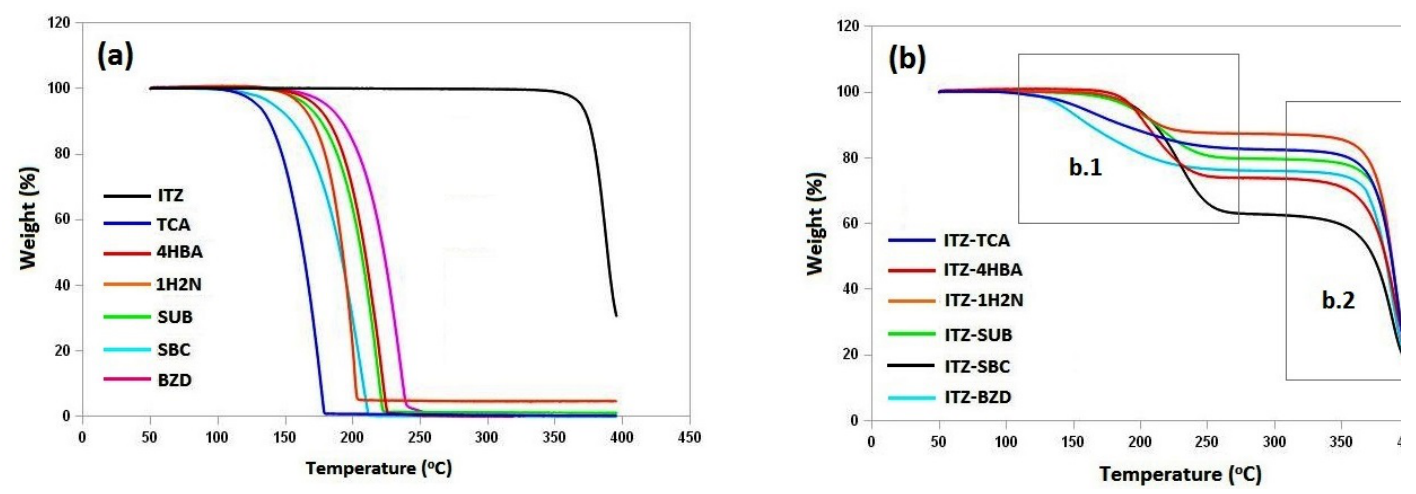

Fig. 4: TGA thermograms of (a) ITZ and coformers and (b) ITZ cocrystals (b.1 indicating zone of coformer's elimination; b. 2 indicating zone of ITZ decompotition or degradation)

Table 4: Theoretical and experimental weight loss analysis in TGA

\begin{tabular}{llll}
\hline Sample & Mole ratio of ITZ: ccf & Theoretical weight loss (\%) & Experimental weight loss (\%) \\
\hline ITZ-TCA & $1: 1$ & 17.35 & 16.99 \\
ITZ-4HBA & $1: 2$ & 28.13 & 26.86 \\
ITZ-SUB & $1: 1$ & 19.80 & 20.20 \\
ITZ-1H2N & $1: 1$ & 21.06 & 18.40 \\
ITZ-SBC & $1: 2$ & 36.44 & 37.10 \\
ITZ-BZD & $1: 2$ & 25.56 & 23.84 \\
\hline
\end{tabular}

TGA was conducted to analyze the changes in cocrystal weight with regards to the changes in temperature (fig. 4a-b). Fig. 4 b shows that TGA curves can be divided into two zones that imply the decomposition of ITZ cocrystals in a two-step process. The first thermal event is a step of weight loss that agreed well (in percentiles) to the coformer composition in cocrystal, indicating that this component (coformer) is released prior to decomposition of the residual ITZ (table 4, fig. 4b). Similar behavior has been reported previously for a series of cocrystals with AMG 517 [32] and acetazolamide [33].

\section{Fourier transform infrared (FTIR) spectroscopy}

Fourier transform infrared (FTIR) spectroscopy analysis can be used to verify the formation of multicomponent crystals. The changes in vibrational frequencies of specific functional groups of the product compared to their starting components can be directly correlated 
with the changes in hydrogen bonding due to formation of multicomponent crystals [34]. The FTIR spectra for ITZ, coformers and ITZ cocrystal are shown in fig. 5a, and table 5 represents the list of relevant IR bands of ITZ, coformers and cocrystals [35]. The comparison of FTIR spectrum between ITZ cocrystals and the starting components showed numerous changes which indicate the obtained new multicomponent crystal.

In the formation of ITZ-TCA, ITZ-4HBA, ITZ-SUB, ITZ-1H2N and ITZ$\mathrm{SBC}$, the changes in $\mathrm{OH}$ stretching frequency imply that these functional groups participate in the hydrogen bonds which resulted in new multicomponent crystals formation. Based on the changes in the frequency of these functional groups, we hypothesized that ITZ and those coformers were involved in strong $\mathrm{OH} \cdots \mathrm{N}$ hydrogen bond to form new multicomponent crystals (fig. 5b). On the other hand, the shifting in spectral peaks have also been observed for the $\mathrm{NH}_{2}$ scissor and rocking mode functional groups in ITZ-BZD which indicate its participation in the hydrogen bonding between the ITZ and BZD. We hypothesized that strong $\mathrm{N}-\mathrm{H} \cdots \mathrm{N}$ hydrogen bond was likely to be involved in the formation of new ITZ-BZD multicomponent crystals (fig. 5b).

FTIR analysis can also be used to determine whether proton transfer from carboxylic acids had occurred, which can be used to differentiate the formed product between salt and cocrystal. Generally, the carbonyl stretch $\mathrm{C}=0$ of carboxylic acid $(\mathrm{COOH})$ showed an intense band at $1750-1680 \mathrm{~cm}^{-1}$. In the formation of a salt species, there was a typical carboxylate anion which have two carbonyl stretching bands, i.e. a strong asymmetrical band below $1600 \mathrm{~cm}^{-1}$ and a weaker symmetrical band near $1400 \mathrm{~cm}^{-1}[35,36]$. The carbonyl group of TCA, 4HBA, SUB, 1H2N and SBC in new ITZ multicomponent crystals exhibits a distinct peak at $1680-1710 \mathrm{~cm}^{-1}$, indicating that the carboxylic acid group is neutral rather than negatively charged. Therefore, proton transfer does not occur between ITZ and organic acids that were used in this study, thus confirming that cocrystal were formed.

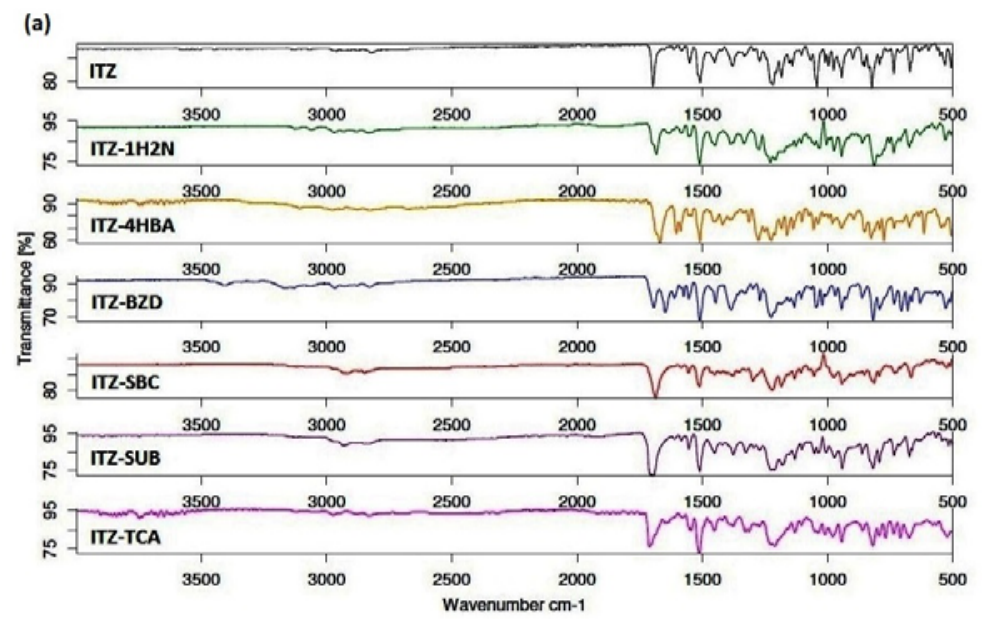

(b)

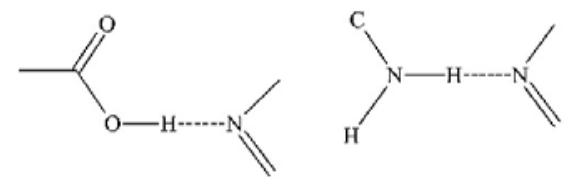

Fig. 5: FTIR spectra of (a) ITZ and its cocrystals and (b) heterosynthons in ITZ cocrystals

Table 5: FTIR stretching frequencies $\left(\mathrm{cm}^{-1}\right)$ of ITZ and its cocrystals

\begin{tabular}{|c|c|c|c|c|c|c|c|}
\hline \multirow[t]{2}{*}{ Functional group } & \multicolumn{7}{|c|}{ Frequency $\left(\mathrm{cm}^{-1}\right)$} \\
\hline & ITZ & ITZ-TCA & ITZ-4HBA & ITZ-SUB & ITZ-1H2N & ITZ-SBC & ITZ-BZD \\
\hline \multirow[t]{3}{*}{ O-H strecth } & - & 2516.71 & 2535.31 & 2524.69 & 2831.40 & 2847.95 & - \\
\hline & & 2820.68 & 2877.87 & 2834.69 & 2931.92 & 2916.41 & \\
\hline & & 2977.47 & 3034.33 & 2932.21 & 2969.35 & & \\
\hline $\mathrm{C}=0$ stretch & 1695.78 & 1710.87 & 1681.41 & 1695.96 & 1683.51 & 1687.38 & 1693.98 \\
\hline C-N stretch & 1452.98 & 1451.88 & 1450.43 & 1451.24 & 1449.67 & 1450.72 & 1447.44 \\
\hline $\mathrm{C}=\mathrm{N}$ stretch & 1613.30 & 1648.81 & 1597.12 & 1610.46 & 1633.23 & 1584.54 & 1647.32 \\
\hline $\mathrm{NH}_{2}$ scissor & - & - & - & - & - & - & 1611.17 \\
\hline $\mathrm{NH}_{2}$ rocking & - & - & - & - & - & - & 1134.04 \\
\hline
\end{tabular}

Table 6: Theoretical and experimental drug content analysis in ITZ cocrystal

\begin{tabular}{lllll}
\hline Sample & Mol ratio & Theoretical & & Experimental \\
\cline { 2 - 4 } & & \% ITZ & \% coformer & \% ITZ \\
\hline ITZ-TCA & $1: 1$ & 82.65 & 17.35 & 83.37 \\
ITZ-4HBA & $1: 2$ & 71.87 & 28.13 & 68.25 \\
ITZ-SUB & $1: 1$ & 80.20 & 19.79 & 80.71 \\
ITZ-1H2N & $1: 1$ & 78.94 & 21.06 & 78.02 \\
ITZ-SBC & $1: 2$ & 63.56 & 36.44 & 61.75 \\
ITZ-BZD & $1: 2$ & 74.44 & 25.56 & 21.98 \\
\hline
\end{tabular}

Determination of drug content 
ITZ content in the ITZ cocrystals was determined by HPLC. The percentage of ITZ content in cocrystals is shown in table 6 .

\section{Analysis of solubility and stability in solution}

Solubility is defined as the concentration of a substance in solution that is at equilibrium with an excess amount of the undissolved substance [37]. Solubility has a significant impact on the bioavailability of API with poor aqueous solubility. ITZ is a BCS class II drug with low aqueous solubility, thus the formation of cocrystal with high aqueous solubility and good stability is desirable to improve its bioavailability. In order to evaluate the solubility of ITZ cocrystals, slurry experiments were performed in $0.1 \mathrm{~N} \mathrm{HCl}$ solution (pH 1.2) at $37^{\circ} \mathrm{C}$ for $24 \mathrm{~h}$ (results are shown in table 7). Solubility of ITZ-BZD and ITZ-SUB could not be determined since the cocrystal was partially converted to ITZ within $24 \mathrm{~h}$ (table 7, fig. 6). ITZ-TCA cocrystal showed the highest solubility, which is 1.97 times higher than the solubility of ITZ. ITZ-SBC cocrystals showed slight improvements in the solubility of ITZ. In the case of other ITZ cocrystals (ITZ-1H2N and ITZ-4HBA), solubility were found to be lower than the solubility of ITZ. It has been previously proposed that cocrystal solubility is directly proportional to the solubility of its components, thus for solubility improvement, it is a common strategy to employ a coformer with a high aqueous solubility in order to cocrystallize with a poorly soluble drug [38]. In this study, coformer solubilities did not show a clear correlation with cocrystal solubilities [39]. It is interesting that the melting point (m. p) of the cocrystals in this study showed a semi-empirical inverse relationship to the solubility (fig. 7). Except for the ITZ-SBC cocrystal, there is an inverse correlation between the melting points of the cocrystals and their solubilities. ITZ-4HBA exhibits the highest melting point and hence the lowest solubility. Similar results have also been reported previously by other researchers for other APIs $[38,40]$.

Table 7: Solubility of ITZ, coformers and ITZ cocrystals in $0.1 \mathrm{~N} \mathrm{HCl}(\mathrm{pH}=1.2)$ at $37^{\circ} \mathrm{C}$

\begin{tabular}{lll}
\hline Sample & Solubility of ITZ or coformers (ppm) & Solubility of ITZ cocrystal (ppm) \\
\hline ITZ & 5 & -- \\
ITZ-TCA & 546 & $9.846 \pm 0.04(\mathrm{x} 1.97)$ \\
ITZ-SBC & 1000 & $5.439 \pm 0.08(\mathrm{x} 1.09)$ \\
ITZ-1H2N & 100 & $2.935 \pm 0.04(\mathrm{x} 0.58)$ \\
ITZ-4HBA & 5000 & $2.307 \pm 0.12(\mathrm{x} 0.46)$ \\
\hline
\end{tabular}

*The values in the parenthesis specifies the extent of increase in solubility of ITZ molecules in cocrystals relative to the pure ITZ

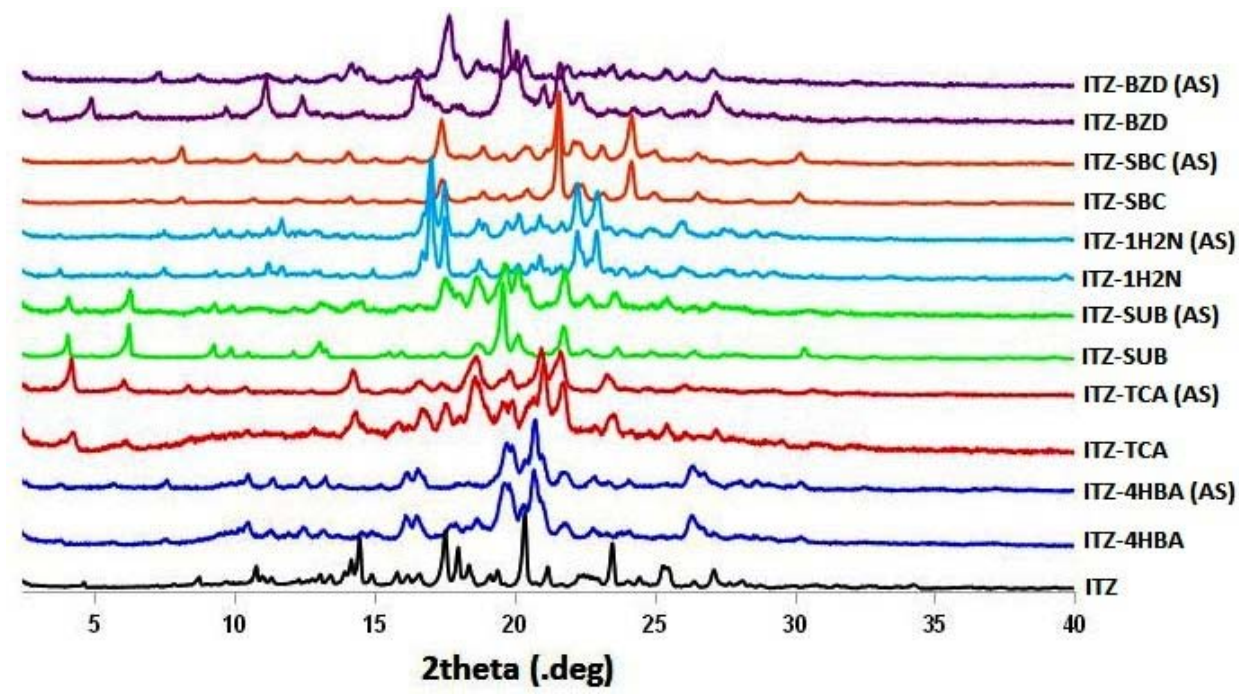

Fig. 6: Powder X-ray diffractograms of ITZ cocrystals before and after solubility study in $0.1 \mathrm{~N} \mathrm{HCl}(\mathrm{pH}=1.2)$ at $37{ }^{\circ} \mathrm{C}(\mathrm{AS})$

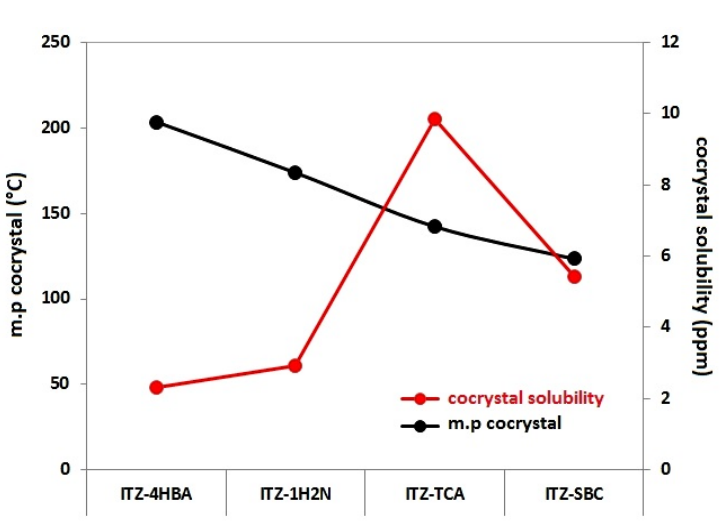

Fig. 7: Correlation plot between solubility of cocrystals vs melting point of cocrystals

\section{CONCLUSION}

In summary, we reported the synthesis of six new cocrystals of itraconazole (ITZ-4HBA, ITZ-TCA, ITZ-SUB, ITZ-SBC, ITZ-1H2N and ITZ-BZD). The solid-state properties of ITZ cocrystals were systematically evaluated by PXRD, DSC, TGA, and FTIR analysis. The solubility of ITZ cocrystals can be either improved or decreased compared to pure ITZ. The improved solubility of ITZ-TCA (1.97-fold), and ITZ-SBC cocrystals (1.09-fold) and decreased the solubility of ITZ$1 \mathrm{H} 2 \mathrm{~N}(0.58$-fold) and ITZ-4HBA cocrystals (0.46-fold) as compared to the pure ITZ were determined after $24 \mathrm{~h}$ in $0.1 \mathrm{~N} \mathrm{HCl}$ solution ( $\mathrm{pH} \mathrm{1.2)}$ at $37{ }^{\circ} \mathrm{C}$. Thus, this study proved cocrystallization to be a promising alternative in positively modifying the solubility of ITZ.

\section{ACKNOWLEDGMENT}

The authors acknowledge Dexa Laboratories of Biomolecular Sciences (DLBS)-PT. DexaMedica for financial support. The authors would like to thank Isabela Anjani for a critical review on this manuscript. 


\section{AUTHORS CONTRIBUTIONS}

All the author have contributed equally

\section{CONFLICT OF INTERESTS}

The authors declared no conflicts of interest with respect to the authorship and/or publication.

\section{REFERENCES}

1. De Beule K. Itraconazole: pharmacology, clinical experience and future development. Int J Antimicrob Agents 1996;6:17581.

2. Peeters J, Nesskens P, Tollenaere JP, Van Remoortere P, Brewster ME. Characterization of the interaction of 2 -

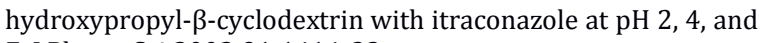
7. J Pharm Sci 2002;91:1414-22.

3. Lee SY, Jung S, Kim JK, Lim GB, Ryu JH. Preparation of itraconazole/HP- $\beta-C D$ inclusion complexes using supercritical aerosol solvent extraction system and their dissolution characteristics. J Supercrit Fluids 2008;44:400-8.

4. Janssens S, Roberts C, Smith EF, Van der Mooter G. Physical stability of ternary solid dispersions of itraconazole in polyethyleneglycol 6000/hydroxypropylmethylcellulose 2910 E5 blends. Int J Pharm 2008;355:100-7.

5. Hong JY, Kim JK, Song YK, Park JS, Kim CK. A new selfemulsifying formulation of itraconazole with improved dissolution and oral absorption. J Controlled Release 2006;110:332-8.

6. Mellaerts R, Mols R, Jammaer JAG, Aerts CA, Annaert P, Van Humbeeck J, et al. Increasing the oral bioavailability of the poorly water-soluble drug itraconazole with ordered mesoporous silica. Eur J Pharm Biopharm 2008;69:223-30.

7. Domingos S, Andre V, Quaresma S, Martins ICB, Piedade MFM, Duarte MT. New forms of old drugs: improving without changing. J Pharm Pharmacol 2015;67:830-46.

8. Zhang S, Lee TWY, Chow AHL. Crystallization of itraconazole polymorphs from melt. Cryst Growth Des 2016;16:3791-801.

9. Zhang S, Britten JF, Chow AHL, Lee TWY. Impact of crystal structure and polymer excipients on the melt crystallization kinetics of itraconazole polymorphs. Cryst Growth Des 2017;17:3433-42.

10. Serajuddin ATM. Salt formation to improve drug solubility. Adv Drug Delivery 2007;1285:603-16.

11. Mittapalli S, Mannava MKC, Kandavilli UBR, Allu S, Nangia A. Soluble salts and cocrystals of clotrimazole. Cryst Growth Des 2015;15:2493-504.

12. Srirambhatla VK, Kraft A, Watt S, Powell AV. Crystal design approaches for the synthesis of paracetamol co-crystals. Cryst Growth Des 2012;12:4870-9.

13. Bolla G, Sanphui P, Nangia A. Solubility advantage of tenoxicam phenolic cocrystals compared to salts. Cryst Growth Des 2013;13:1988-2003.

14. Stephenson GA, Aburub A, Woods TA. Physical stability of salts of weak bases in the solid-state. J Pharm Sci 2011;100:1607-17.

15. Aitipamula S, Banerjee R, Bansal AK, Biradha K, Cheney ML, Choudhury AR, et al. Polymorphs, salts, and cocrystals: what's in a name? Cryst Growth Des 2012;12:2147-52.

16. Hiendrawan S, Hartanti AW, Veriansyah B, Widjojokusumo E, Tjandrawinata RR. Solubility enhancement of ketoconazole via salt and cocrystal formation. Int J Pharm Pharm Sci 2015;7:160-4.

17. Gao Y, Gao J, Liu Z, Kan H, Zu H, Sun W, et al. Coformer selection based on degradation pathway of drugs: a case study of adefovir dipivoxil-saccharin and adefovir dipivoxilnicotinamide cocrystals. Int J Pharm 2012;438:327-35.

18. Wang ZZ, Chen JM, Lu TB. Enhancing the hygroscopic stability of S-Oxiracetam via pharmaceutical cocrystal. Cryst Growth Des 2012;12:4562-6.

19. Hiendrawan S, Veriansyah B, Widjojokusumo E, Soewandhi SN, Wikarsa S, Tjandrawinata RR. Simultaneous cocrystallization and micronization of paracetamol-dipicolinic acid cocrystal by supercritical antisolvent (SAS). Int J Pharm Pharm Sci 2016;8:89-98.

20. Cheney ML, Shan N, Healey ER, Hanna M, Wojtas L, Zaworotko $\mathrm{MJ}$, et al. Effects of crystal form on solubility and pharmacokinetics: a crystal engineering case study of lamotrigine. Cryst Growth Des 2010;10:394-405.

21. Trask AV. An overview of pharmaceutical cocrystals as intellectual property. Mol Pharm 2007;4:301-9.

22. Remenar JF, Morissette SL, Peterson ML, Moulton B, MacPhee JM, Guzmán HR, et al. Crystal engineering of novel cocrystals of a triazole drug with 1,4-dicarboxylic acids. J Am Chem Soc 2003;125:8456-7.

23. Tarsa PB, Towler CS, Woollam G, Berghausen J. The influence of aqueous content in small-scale salt screening-improving hit rate for weakly basic, low solubility drugs. Eur J Pharm Sci 2010;41:23-30.

24. Kumar N, Shishu, Bansal G, Kumar S, Jana AK. Ditosylate salt of itraconazole and dissolution enhancement using cyclodextrins. AAPS PharmSciTech 2012;13:863-74.

25. Shevchenko S, Miroshnyk I, Pietila LO, Haarala J, Salmia J, Sinervo $\mathrm{K}$, et al. Diversity in itraconazole cocrystals with aliphatic dicarboxylic acids of varying chain length. Cryst Growth Des 2013;13:4877-84.

26. Munde AV, Kumar FN, Radheshyam BK. Co-crystallization: an alternative approach for solid modification. J Drug Ther 2013;3:166-72.

27. Cruz-Cabeza AJ. Acid-base crystalline complexes and the pKa rule. Cryst Eng Comm 2012;14:6362-5.

28. Hiendrawan S, Veriansyah B, Widjojokusumo E, Soewandhi SN Wikarsa S, Tjandrawinata RR. Physicochemical and mechanical properties of paracetamol cocrystal with 5-nitroisophthalic acid. Int J Pharm 2016;497:106-13.

29. Huang Y, Zhang B, Gao Y, Zhang J, Shi L. Baicalein-nicotinamide cocrystal with enhanced solubility, dissolution, and oral bioavailability. J Pharm Sci 2014;103:2330-7.

30. Mulye SP, Jamadar SA, Karekar PS, Pore YV, Dhawale SC Improvement in physicochemical properties of ezetimibe using a crystal engineering technique. Powder Technol 2012;222:131-8.

31. Perlovich GL. Thermodynamic characteristics of cocrystal formation and melting points for rational design of pharmaceutical two-component systems. Cryst Eng Comm 2015;17:7019-28.

32. Stanton MK, Bak A. Physicochemical properties of pharmaceutical co-crystals: a case study of ten AMG 517 cocrystals. Cryst Growth Des 2008;8:3856-62.

33. Jenniffer IAG, Dea HR, Rojas HM, Hopfl H. Interrelation of the dissolution behavior and solid-state features of acetazolamide cocrystals. Eur J Pharm Sci 2017;96:299-308.

34. Chadha R, Saini, Jain ADS, Venugopalan P. Preparation and solidstate characterization of three novel multicomponent solid forms of oxcarbazepine: improvement in solubility through saccharin cocrystal. Cryst Growth Des 2012;12:4211-24.

35. Demiana IN. Formulation and evaluation of itraconazole via liquid crystal for topical delivery system. J Pharm Biomed Anal 2001;26:387-99.

36. Brittain HG. Vibrational spectroscopic studies of cocrystals and salts.3. cocrystal products formed by benzenecarboxylic acids and their sodium salts. Cryst Growth Des 2010;10:1990-2003.

37. Luo YH, Sun BW. Pharmaceutical co-crystals of pyrazinecarboxamide (PZA) with various carboxylic acids: crystallography, hirshfeld surfaces, and dissolution study. Cryst Growth Des 2013;13:2098-106.

38. Chow SF, Shi L, Ng WW, Leung KHY, Nagapudi K, Sun CC, et al. Kinetic entrapment of a hidden curcumin cocrystal with phloroglucinol. Cryst Growth Des 2014;14:5079-89.

39. Goud NR, Gangavaram S, Suresh K, Pal S, Manjunatha SG, Nambiar S, et al. Novel furosemide cocrystals and selection of high solubility drug forms. J Pharm Sci 2012;101:664-80.

40. Maddileti D, Jayabun SK, Nangia A. Soluble cocrystals of the xanthine oxidase inhibitor febuxostat. Cryst Growth Des 2013;13:3188-96. 